\title{
TESTING THE 60 MJ PULSED HOMOPOLAR POWER SUPPLY AT THE UNIVERSITY OF TEXAS, CENTER FOR ELECTROMECHANICS
}

By:

\author{
J. R. Kitzmiller \\ J. H. Gully \\ M. L. Spann \\ W. F. Weldon \\ D. J. Wehrlen
}

Proceedings of the 7th IEEE Pulsed Power Conference, Monterey, CA, June 11-14, 1989, pp. 645-649 


\title{
TESTING THE 60 MJ PULSED HOMOPOLAR POWER SUPPLY AT THE UNIVERSITY OF TEXAS CENTER FOR ELECTROMECHANICS
}

\author{
J.R.Kitzmiller, J.H.Gully, M.L.Spann, W.F.Weldon, D.J.Wehrlen
}

\author{
The Center for Electromechanics \\ The University of Texas at Austin \\ Austin, Tx. 78758-4497
}

\begin{abstract}
The Center for Electromechanics at the University of Texas at Austin (CEM-UT) has successfully designed, built, and tested homopolar generators (HPGs) since 1972. These machines exhibit high energy storage densities and are capable of converting stored inertial energy to electrical energy at extremely high power levels. This feature makes them well suited for for a wide range of applications including thermonuclear fusion, resistance welding, pulse sintering, and electromagnetic launchers. In December 1988, CEM-UT along with Parker Kinetic Designs, Inc. (PKD) completed acceptance testing of the latest in this technology: the Balcones $60 \mathrm{MJ}$ pulsed homopolar generator power supply (BHPG). This power supply is presently capable of producing $9 \mathrm{MA}$ at $100 \mathrm{~V}$.
\end{abstract}

This paper describes the BHPG systems and operating characteristics. Data is presented from commissioning short circuit tests for the six generator system, including single and multiple generator tests, as well as system performance levels during railgun solid armature tests.

\section{Introduction}

The BHPG system is a sophisticated combination of unique state of the art pulsed power equipment. The system includes six $10 \mathrm{M}$ ] truncated drum-type HPGs $[1,2,3,4]$ (each rated at $100 \mathrm{~V}$ and $1.5 \mathrm{MA}$ ); extensive auxiliary support systems [5]; six $6.5 \mu \mathrm{H} 100 \mathrm{kV}$ two turn coaxial room temperature inductors (rated to $1.22 \mathrm{MA}$ each) [6,7]; six explosive monolithic opening switch units with containment vessels [8]; and a very sophisticated data acquisition and system controller [5].

The fully operational status of the BHPG system has only recently been achieved (November, 1988). However, since the system was initially installed and commissioning was begun with the first generator discharged in September 1986, literally hundreds of tests have been made on the system at wide ranges of generator configurations and system energies ranging from $250 \mathrm{~kJ}$ to $60 \mathrm{MJ}$. The loads varied for these tests; most frequently it was a resistive load with considerable inductance $(>6 \mu \mathrm{H})$, and at times the load was a large caliber railgun with time-varying inductance and resistance. During this time also, some interesting mechanical anomalies developed inside the generators which had to be resolved before commissioning continued [9]

To date, the system has demonstrated power levels to $3 \mathrm{GW}$ and has logged hundreds of runs. Peak power levels approaching five times this are easily within reach so far as the system is concerned. The purpose of this paper is to concisely homogenize the information presented in the previous listed references and to provide more recent and complete test data obtained from the system as a whole. This paper will describe the capabilities of the BHPG system and the versatility obtained with its use in general high power pulsed experiments. The data presented will come from three different load sources for the generators. Included here are high resistance low impedance commissioning loads, high resistance and high impedance commissioning loads, and time varying resistance and impedance loads from large caliber solid armature railgun tests.

\section{BHPG Facilities and System Description}

The Balcones $60 \mathrm{MJ}$ homopolar power supply (fig. 1) is comprised of five major systems: 1) six truncated drum type HPGs and output buswork; 2) auxiliary systems; 3 ) six $6.2 \mu \mathrm{H}$ room temperature inductors and high power explosive opening and closing switches; 4) instrumentation and controls; and 5) data acquisition and processing systems.

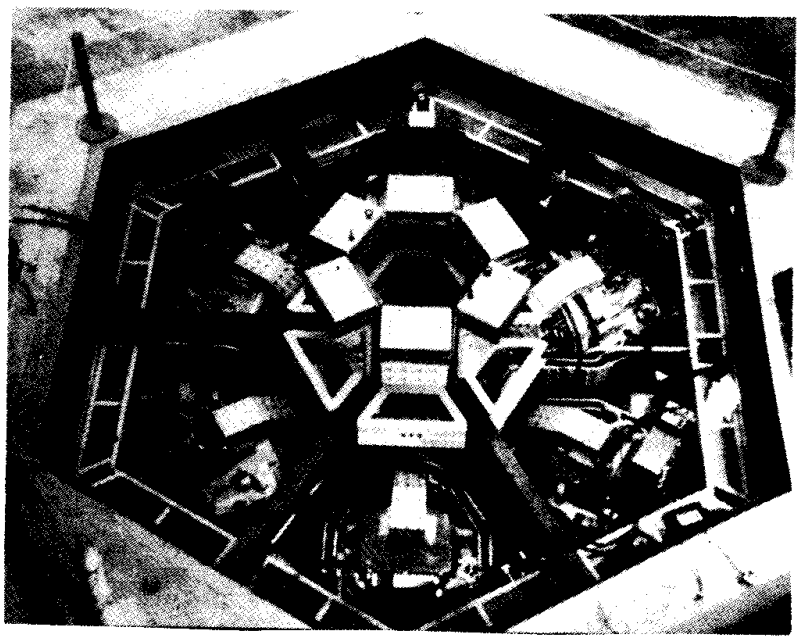

Figure 1. BHPG $60 \mathrm{MJ}$ HPGs

\section{Generator Design}

The heart of the BHPG system is the six truncated drum-type HPGs. Figure 2 shows a cross-sectional view of a generator with the busbars installed. These 10-MJ generators are each capable of producing a 1.5 MA peak current pulse at $100 \mathrm{~V}$ open circuit at $6,050 \mathrm{rpm}$. A list of the generator general specifications is provided in table 1 . These robust iron-core machines feature an E4340 rotor thermally fit onto a nitronic 50 stainless steel shaft which minimizes magnetic flux entrainment in the bearing regions. The rotor is supported by two radial orifice compensated hydrostatic bearings and a single opposed pad orifice compensated hydrostatic thrust bearing. The generators operate subcritically with a measured fundamental bending frequency of over $14,000 \mathrm{rpm}$ and the first axial critical speed at about $8,100 \mathrm{rpm}$. The two piece cast A27 Grade stator houses dual water cooled, series connected field coils which produce 67,200 amp-turns of magnetomotive force at $1,200 \mathrm{~A}$ excitation current. Only $900 \mathrm{~A}$ is required to provide 1.8 $\mathrm{T}$ average field density in the rotor air gaps. Water cooled ETP-110 copper compensating turns deliver the current collected by the 294 pneumatically operated main brushes, which are also used as the closing switches for the generator. Generator voltage is read from isolated instrument brushes which are attached to the main brush sectors inside the generator. All generator busbars are made from ETP110 copper. The output busbars on the generators are a compensated flat plate arrangement $(1.00 \mathrm{in}$. [2.54 cm] thick by $12 \mathrm{in}$. $[0.305 \mathrm{~m}]$ wide $)$. Four pairs of these busbars form the output spider, which is connected to the main compensated vertical bus rack through a pair of horizontal coaxial copper tubes. The vertical bus riser conductors are 2 in. $(5.08 \mathrm{~cm}$ ) thick and 24 in. $(0.610 \mathrm{~m})$ wide. These machines have proven to be of a very durable design and should provide for years of reliable service.

\section{Auxiliary Systems}

The generator auxiliary systems include three hydraulic motoring skids, electric and diesel driven hydrostatic bearing supply skids, conditioned air compressor used for brush sector cooling, brush actuator nitrogen gas supply, field coil power supply skids, and the field coil/compensating turn liquid cooling skid. 


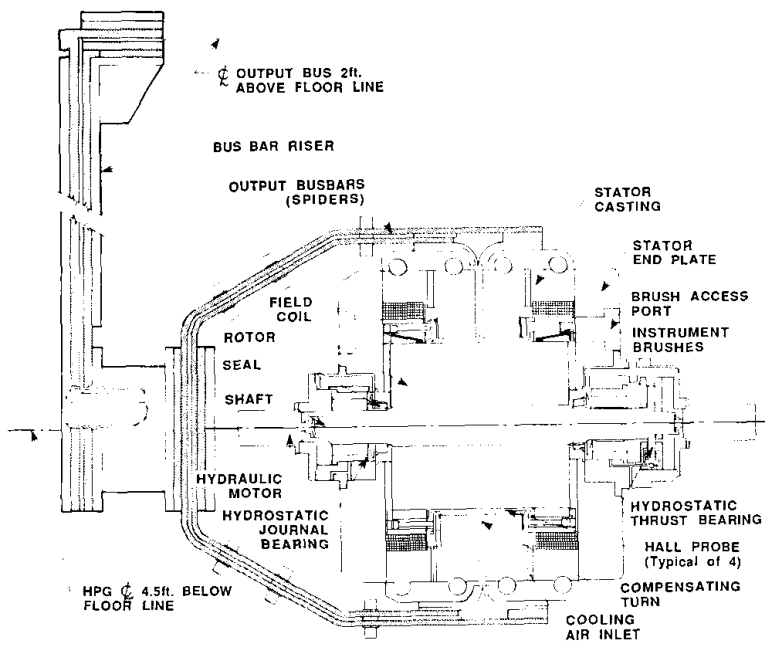

Figure 2. Cross sectional view of the BHPGs (with busbars)

Table 1. 10 MJ truncated drum HPG parameters

\begin{tabular}{|l|c|c|}
\hline \multicolumn{1}{|c|}{ PARAMETER } & VALUE & UNITS \\
\hline Peak Current & 1,500 & $\mathrm{kA}$ \\
\hline Open Circuit Voltage & 100 & $\mathrm{~V}$ \\
\hline Effective Capacitance & 2,000 & $\mathrm{~F}$ \\
\hline Internal Resistance & 6 & $\mu \Omega$ \\
\hline Internal Inductance & 112 & $\mathrm{nH}$ \\
\hline Maximum Rotor Speed & 6,200 & $\mathrm{rpm}$ \\
\hline Maximum Slip Ring Speed & 186 & $\mathrm{~m} / \mathrm{s}$ \\
\hline Rotor Inertia & 49.2 & $\mathrm{~kg}-\mathrm{m}^{2}$ \\
\hline Rotor Diameter & 0.57 & $\mathrm{~m}$ \\
\hline Rotor Length & 0.59 & $\mathrm{~m}$ \\
\hline Rotor Mass & 1,200 & $\mathrm{~kg}$ \\
\hline Stator Diameter & 1.07 & $\mathrm{~m}$ \\
\hline Stator Length with End Caps & 1.24 & $\mathrm{~m}$ \\
\hline Stator Mass with End Caps & 6,820 & $\mathrm{~kg}$ \\
\hline Total Generator Length & 1.95 & $\mathrm{~m}$ \\
\hline Length Including Bus & 2.0 & $\mathrm{~m}$ \\
\hline $\begin{array}{l}\text { Total Generator Weight } \\
\text { (less busbars) }\end{array}$ & 7,945 & $\mathrm{~kg}$ \\
\hline $\begin{array}{l}\text { Impedance (includes busbars) } \\
\text { Magnetic Flux Density in Air }\end{array}$ & 7.1 & $\mathrm{~m} \Omega$ \\
\hline $\begin{array}{l}\text { Gaps } \\
\mathrm{nH}\end{array}$ & 1.8 & $\mathrm{~T}$ \\
\hline
\end{tabular}

Motoring of the six generators is accomplished with a 2,400 hp $(1.8 \mathrm{MW})$ closed loop hydraulic system made up of six servo-controlled variable displacement axial piston pumps (Rexroth Corp.) which drive twelve (two per generator) fixed displacement axial piston motors (Sunstrand Corp.). The main pumps and motors operate at a maximum system pressure of $5,800 \mathrm{psi}(400 \mathrm{BAR})$ and a maximum flow rate of 120 $\mathrm{gpm}(454 \mathrm{l} / \mathrm{min})$ per generator. The motoring system features an electrohydraulic speed control system (EHC) which monitors and adjusts each generator's speed as required to maintain each generator within a specified speed tolerance window.

The hydrostatic bearings are supplied oil both by an electric driven pump and a redundant, fail-safe, diesel driven pump. Both the electric motor and diesel are rated at $250 \mathrm{hp}(187 \mathrm{~kW})$. Each prime mover drives a rotary screw type pump (Trans-America Delaval Corp.) which delivers $240 \mathrm{gpm}(908 \mathrm{l} / \mathrm{min}$ ) hydraulic oil at 1,500 psig (103 bar) to the six generators. Also included in this system is a 1,320 gal (4,994 l) bearing oil tank and a 300 gal $(1,1351)$ diesel fuel tank. The returning bearing oil is cooled with dual chilled water heat exchangers before reentering the bearing tank.

The $250 \mathrm{hp}(187 \mathrm{~kW})$ conditioned air compressor is used only during the discharge sequence of the generators. At discharge, the generator rotor cavities are flooded with conditioned dry a.r to help purge the rotor cavity area of brush debris during and after the pulse. The air also acts to cool the brush sectors. The system featt res a 100 psig compressor which will flow $1,200 \mathrm{cfm}$ air through an air drying unitization unit (ADU). The ADU consists of a single pass aftercooler which cools the air from $100^{\circ} \mathrm{F}$ to $55^{\circ} \mathrm{F}$, a combination centrifugal separator/trap which removes water vapor and other entrainrents and discharges them into a drain pipe, and a coalescing filter which is used to clean the air and remove still more moisture. This fi ter traps impurities as well as moisture, which is coalesced and drained off passively. The air is then reheated to room temperalure $\left(80^{\prime \prime} \mathrm{F}\right)$ before passing into the generators.

The field coil power supply system consists of six $150 \mathrm{kVJ}(900 \mathrm{~kW}$ total) SCR controlled dc power supplies (Rapid Electric Corp.). The dc output from each power supply is controllable between 0 and $12.5 \mathrm{~V}$ and 0 and 1,200 A. Each unit has built in circuit protection for such things as over-temperature and overload conditions.

The field coil and compensating turn cooling water system is designed to provide a room temperature supply of cooling water solution to the generators between discharges. This water circulates ir. the field coils and compensating turn conductors and removes enough heat to rate the system for a 5 min discharge cycle. The system is made up of a 7.5 hp motor driving a vane pump. A pneumatically controlled modulating valve regulates flow of the remotely available chilled water supply to the heat exchanger, based on feedback from a thermocouple located in the cooling water output line. Cooling water pressure is governed by a pressure regulating valve located after the vain pump. A 25 micron filter is used to trap any impurities in the system.

\section{Inductors and Opening Switches}

Intermediate energy storage for the BHPG pulsed power supply consists of six $6.5 \mu \mathrm{H}$, room temperature copper coaxial inductors, designed to operate at $1.22 \mathrm{MA}$ and withstand $100 \mathrm{kV}$. Each inductor has a dc resistance of $9.8 \mu \Omega$, an outer diameter of $1.4 \mathrm{~m}(55 \mathrm{in.}$, , an over all length of $5.0 \mathrm{~m}(199.5 \mathrm{in}$.), and a total mass of $11,124 \mathrm{~kg}(24,256 \mathrm{lb})$.

The inductors feature a two turn coaxial geometry fabricated of copper alloy CDA 10300 . A bolted flange at the base allows easy access for inspecting and replacing the insulation. The coaxial inductors are comprised of four nested "cylinders." The inner cylinder is a $17.8 \mathrm{~cm}$ (7 in.) rod, $506.7 \mathrm{~cm}$ (199.5 in.) long, with a $5 \mathrm{~cm}(2 \mathrm{in}$.) hole in the center to allow for liquid nitrogen cooling, which would provide a $4 \%$ decrease in resistance.

The BHPG system monolithic explosive opening switches are described in detail in a paper presented by R. L. Sledge et. al. in these proceedings entitled, "Experimental Data on High Power Explosive Opening and Closing Switches at CEM-UT."

\section{Instrumentation and Controls}

For the purpose of data recording and real time control, various machine parameters are measured. The instrumentation package consists of 170 analog signals which originate either at a genera tor or at the auxiliary subsystem level. Signal sources include RTIDs, Hall probes, strain gauges, Rogowski coils, and voltage attenuators. Seventy-two of these signals are displayed to the operator $\mathrm{b} y$ digital panel meters (Dixon Instruments) which also include setpoin s which are used by various controllers.

Signal transmission is done over 4 to $20 \mathrm{~mA}$ current loops using foil wrapped, shielded twisted pairs which are enclosed in steel conduit. In anticipation of the experimental noise levels, all signal conditioners are mounted in EMI/RFI attenuating enclosures and are located as close to the signal source as possible. All signal measurements ate made across $250 \Omega, 0.1 \%$ resistors within the RF screened control room. Millivolt-to-current loop conversions are accomplished by a nodular signal conditioner subsystem (3B series, manufactured by Analog 
Devices). This subsystem provides a wide range of functionally complete, plug-in modules which accommodate a variety of input signals.

System control is accomplished using nine General Electric Series III programmable controllers (PC) and a solid state, hard-wire-logic critical fault controller (CFC, manufactured by Trip Alarm). Six of the PC's are dedicated to individual HPGs while the remaining three PC's coordinate the control of all system auxiliaries and group control of all selected machines. All control operations and possible faults for the BHPG system are grouped as either critical or noncritical, with critical faults and operations being those which could result in permanent damage to a generator or danger to personnel.

The CFC uses a unique field wiring system which is able to distinguish between a simple transducer failure and a real machine fault. In the event of a critical fault the CFC will initiate a brakerotor state without operator intervention. If the fault is sufficiently severe, then the CFC is also able to initiate an emergency discharge which will stop all rotor motion (from full speed) within $200 \mathrm{~ms}$ for most loads. All of the remaining noncritical operations (motoring skid start-up, electric bearing skip start-up, diesel bearing skid warm-up, etc) and faults (failure to synchronize voltage, loss of motoring press, charge pressure low, etc.) are controlled by the three system PC's.

\section{Data.Acquisition Sub-System (DASS)}

During any BHPG discharge into an experimental load, data is collected in two different locations. Generator data (HPG voltage, speed, and current) is collected by the BHPG DASS. The BHPG DASS is a dedicated system which is permanently patched into all BHPGs. All load and bus data is collected on the shot DASS. This group of digitizers and digital scopes is patched as needed for each shot.

All stand-alone digitizers used at CEM-UT are CAMAC standard modules. The CAMAC standard (IEEE \#675) uses a fixed configuration, 25 slot backplane and power supply (defined as a crate) into which a wide variety of function modules are installed. The CAMAC backplane uses a 24 bit data bus and and a 16 bit function bus with a 4 bit subfunction bus. Addressing is accomplished using a master-slave scheme. Slots 24 and 25 are the crate controller position and slots 1 to 23 are slave positions. A dedicated address line is wired between each of the 23 slave positions to the dual controller position. Multislot CAMAC modules are addressed by a single line as designated by the manufacturer. By CAMAC standard, the module slot number is referred to as "N".

Once collected on digitizer or digital oscilloscope, all data is transferred to a Digital Equipment Corp. VaxStation II GPX standalone micro-computer using the general purpose interface bus (GPIB, IEEE\# 488). The GPIB data bus was chosen for a variety of reasons. GPIB is a very fast bus ( $>500$ kbaud) with an excellent reputation for reliability. GPIB is also very widely used by electronics manufacturers of computer compatible test equipment which makes communications interfacing very easy.

The BHPG DASS consists of two CAMAC crates. The first crate contains a DSP TRAQ system with 24 input channels. These digitizers record brush voltage, output bus voltage, and output current for each of the six HPGs using a $50 \mathrm{kHz}$ sample rate. Also in the first crate are two AEON \#3232 digitizers with 32 input channels and two Aeon 7064 memories each. These digitizers record all data relevant to the motoring interval. This includes individual machine bearing oil pressure, motoring oil pressure, bearing oil temperature, motoring oil temperature, analog rotor speed, etc. The motoring data is recorded using a $5 \mathrm{~Hz}$ sample rate. Located in the second crate, a block of 13 CAMAC modules are used to digitally record a very accurate rotor speed measurement. This block consists of six LeCroy 3521 scaling modules, six LeCroy 8206A memory modules, and one LeCroy 8501 clock module. The rotor speed comes into the screen room as a 30 pulse per revolution tach. The 3521 counts the number of $1 \mathrm{MHz}$ clock cycles between tach pulses and then stores each result into the memory. This direct measurement of rotor period is easily converted into an "rpm" format by the collecting software. The final AEON 3232 in the second crate is used to record four HPG field coil Hall probes per machine.
CEM-UT has developed an extensive library of software subroutines for communications between the VaxStation II and GPIB compatible lab equipment. This includes digital scopes, strain-gauge controllers, micro-positioners, laser position sensors, and approximately 15 different CAMAC modules. In addition to communications subroutines, it was also necessary to develop a set of data collection and post-experiment processing software which allowed a maximum number of functions with a minimum chance for data loss or confusion.

\section{BHPG Characteristics and Performance}

The BHPG system has a total mechanical energy storage of $60 \mathrm{MJ}$. During a discharge of a single machine into a system inductor, a transfer efficiency of $46 \%$ has been realized. This results in a maximum of 27.6 MJ of electrical storage in the six pulse shaping inductors. While this is the maximum energy which is available to a load from the inductors, the full system energy of $60 \mathrm{MJ}$ is currently available to a load if the system inductors are not required for pulse shaping. Also, the possibility of higher speed operation, with system energies to $90 \mathrm{MJ}$ exists.

Currently, two busbar systems attached to a large HPG current collection turret are used for attaching pulsed power experiments. Besides powering railgun experiments, the power supply has also been used for running experiments to aid in the development of advanced compulsators. In particular, shaft transient eddy current generation present in two pole air core compulsators is presently being studied. Additionally, the BHPG system will be used as the power supply for a single turn toroidal field coil. This coil is part of a nuclear fusion experiment, the details of which are explained in another paper at these proceedings by M.D. Werst, et.al., entitled, "Homopolar Generator Powered High Field Magnet Experiment for the Ignitex Fusion Device." The generators will be delivering the full rated $9 \mathrm{MA}$ during this experiment. If desired, the opening switches and inductors can be easily removed and an experiment can be directly connected to a single (or multiple) generator.

During both start-up testing and experimental discharges of the system, the generators have used two primary discharge modes. First is a direct discharge into the experimental load, which results in maximum energy transfer but also results in rather long pulse widths (hundreds of milliseconds). The second mode involves discharging into the system inductors with the switch element initially acting as a short circuit (while charging the inductors to full current), and later opening to commutate current into the load.

During a "short circuit" discharge of this nature, the overall circuit parameters would result in reverse motoring of the HPG if the circuit impedance was not modified through the use of an explosive opening switch. In the event the switch explosives fail to detonate, the switch element is sized to open the circuit passively as a result of resistive heating. The switch design has proven its ability to prevent reverse motoring by passive opening during a 1.22-MA discharge.

CEM-UT has engaged in the long term development of opening switches for the efficient control of high current transient pulses. Using data obtained during discharges into several different EML and static loads, the switches employed by the BHPG power supply have been revised several times and are currently capable of delivering switching efficiencies as high as $94 \%$. Lower efficiency (on the order of 85 to $90 \%$ ) results when discharging into higher impedance loads. Opening times on the order of $100 \mu \mathrm{s}$ are routinely achieved, however, this varies as a function of load impedance, number of gaps which are opened in the switch, and total current in the switch plate at the time of opening.

\section{BHPG Test Data}

The purpose of this section is to present representative test data from the discharge testing of the Balcones homopolar generators. Figure 3 shows a characteristic family of curves for a discharge of BHPG \#2 into a stainless steel test resistor which is bolted into the normal opening switch position. This is a full speed discharge from $6,050 \mathrm{rpm}$ which results in a peak current of approximately $602 \mathrm{kA}$ (for this resistive load) and an open circuit voltage of approximately $100 \mathrm{~V}$. 


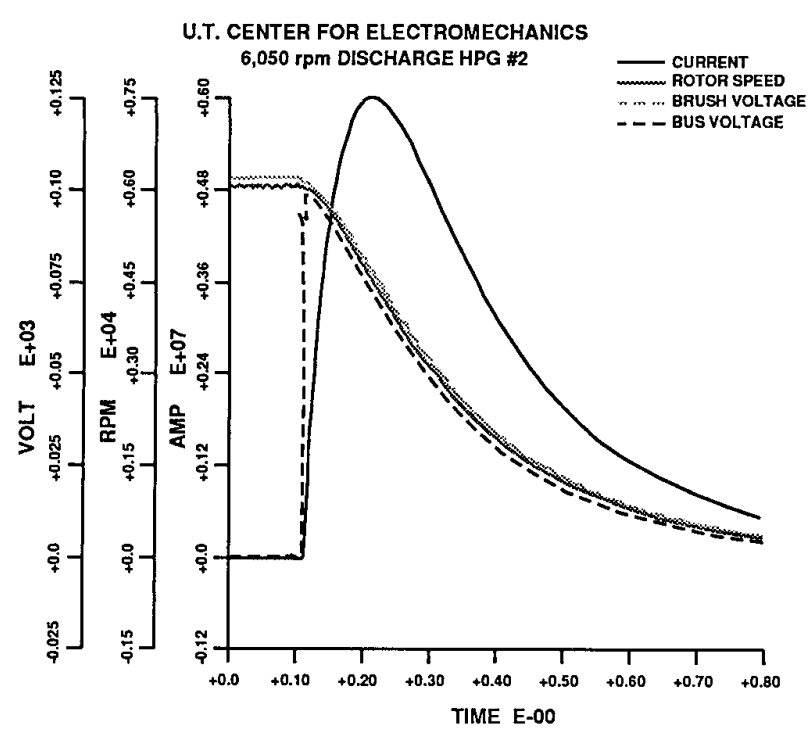

2201.0007

Figure 3. Data from full 6,050 rpm discharge of HPG \#2 into inductor and stainless steel test resistor

Figure 4 shows the six discharge currents for the final full energy acceptance test which was performed on December 9, 1988. The test loads for this experiment were six independent stainless steel resistors identical to the single resistor used in figure 3 . The discharge parameters for all six machines were the same as shown in the previous case within $2 \%$.

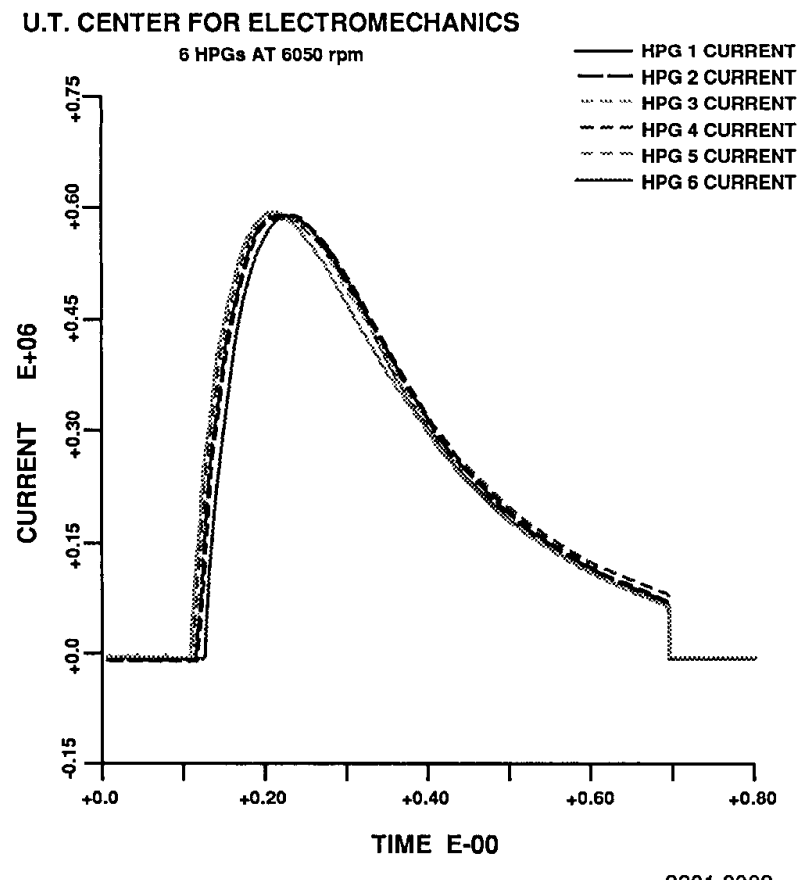

Figure 4. All six generator discharged into inductors and stainless steel test resistors from $6,050 \mathrm{rpm}$
Next, figure 5 shows the complete family of curves for 13HPG \#1 from a full current discharge performed December 14, 1988. A single generator was used for this discharge for two reasons. Firs,t, a load which could withstand the full discharge energy of $60 \mathrm{MJ}$ was unavailable. Second, it was undesirable to put more than a single generator at risk during the first full current test. The peals current obtained for this discharge was 1.22 MA.

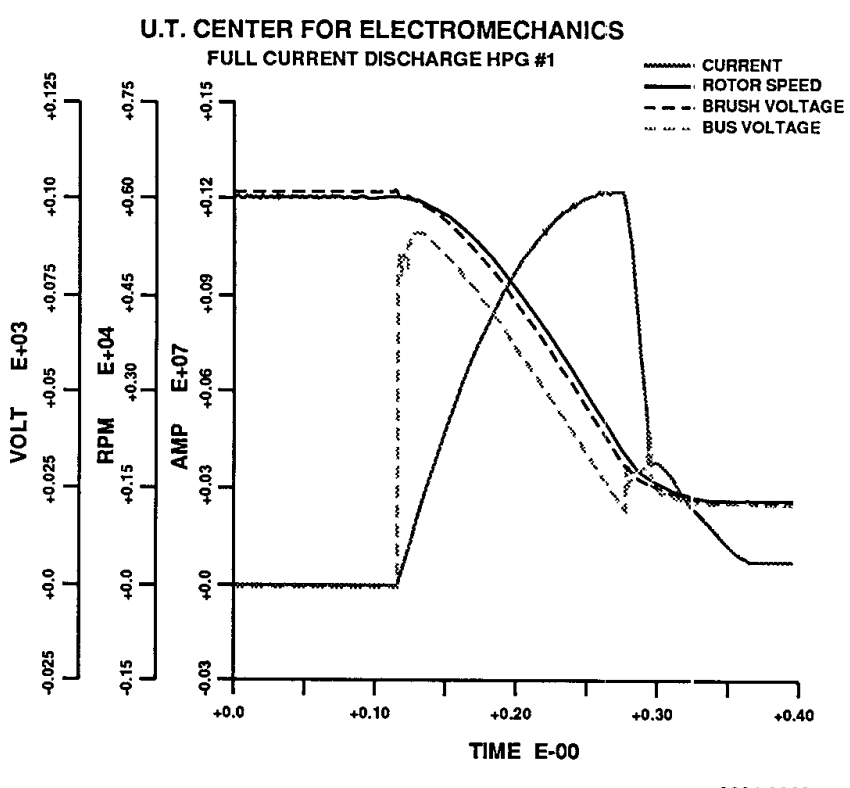

Figure 5. 1.22 MA discharge on HPG $\$ 1$

Finally, three separate data plots are shown for a six zenerator BHPG discharge which staged three generators at time zero tis provide an initial current of $2.84 \mathrm{MA}$ into a large bore solid-armature railgun. The three remaining generators were then staged individually to support the current waveform. The peak current into the load was 3.21 MA.

Figure 6 shows each of the six inductor currents plottecl with the total load current. Figure 7 shows each of the six switch currents which have also been plotted with the load current for easy reference. The mean switching time for the data shown is $140 \mu \mathrm{s}$. The stagng of the three subsequent generators can be clearly seen on these two plots.

Because the energy and power available from the BHI'G power supply is of extreme interest to the community, figure 8 shows the instantaneous power and total energy delivered to the load. During this discharge, a total energy of $13.8 \mathrm{MJ}$ was provided to the load with an instantaneous peak power of $13.2 \mathrm{GW}$ and an average power of approximately $3.2 \mathrm{GW}$.

\section{Conclusion}

The $60 \mathrm{MJ}$ BHPG system is now fully operational at CEM-UT. The robust iron core HPG based power supply is capable of delivering $9 \mathrm{MA}$ at $100 \mathrm{~V}$, and in combination with the energy storage inductors and explosive opening switches, the system can readily cperate at multigigawatt power levels. Flexibility designed into the system allows for a wide range of pulsed power experiments to be run, with extensive data acquisition hardware and processing softwa:e readily available for comprehensive data reduction. The power supply is routinely being used for high energy railgun experiments, is well as experiments for the development of advanced compulsator designs, and nuclear fusion related experiments. 


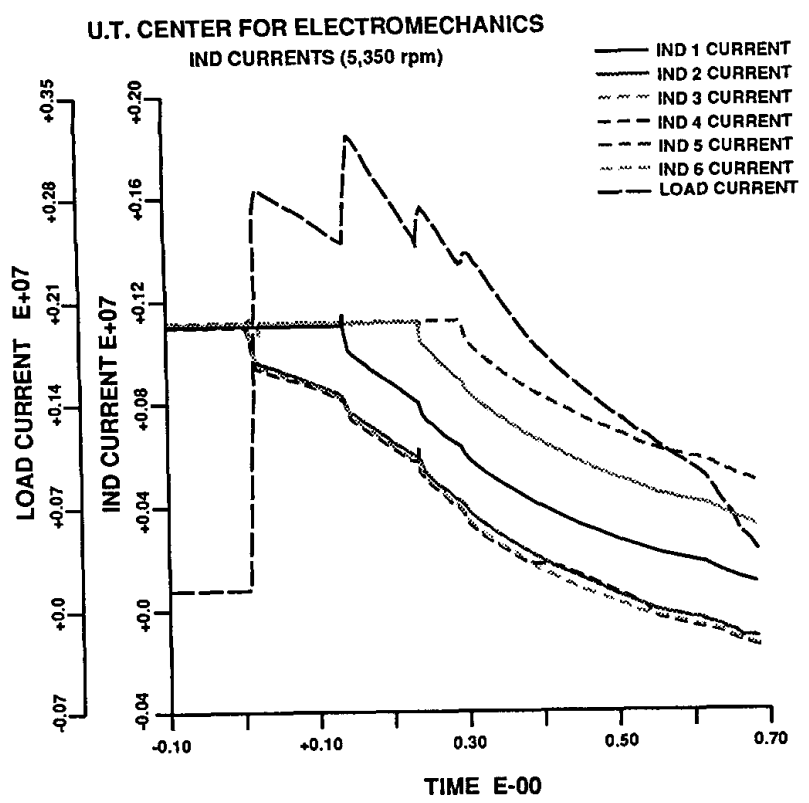

2201.0010

Figure 6. Six generator discharge, three at time zero and three staged, into large bore solid armature railgun

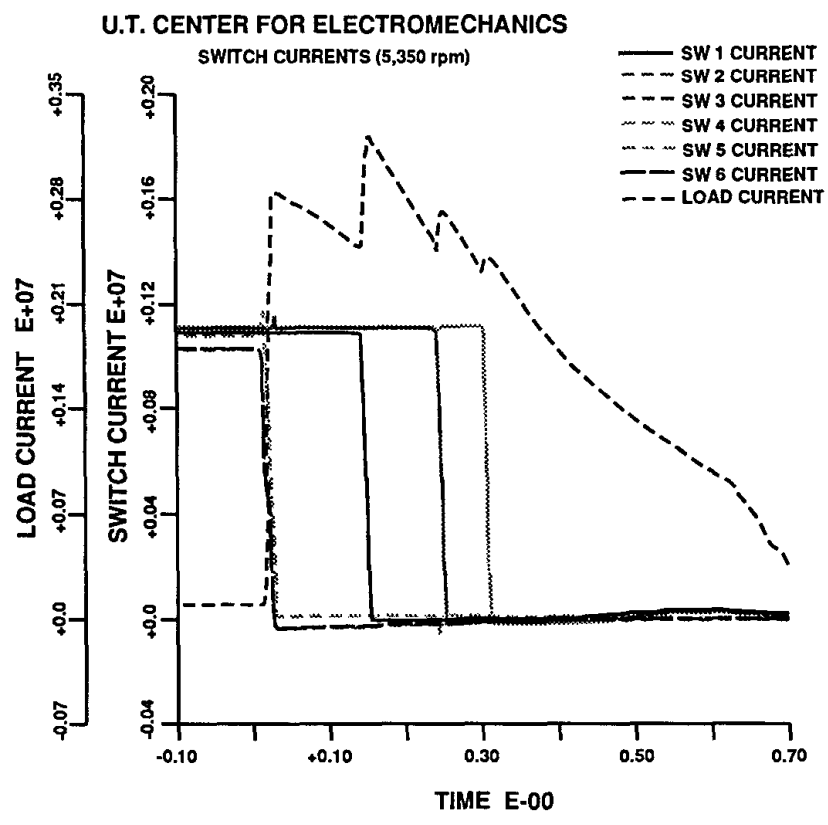

Figure 7. Same as figure 6, with switch currents overlaid

Funding for this program was provided by The University of Texas at Austin.

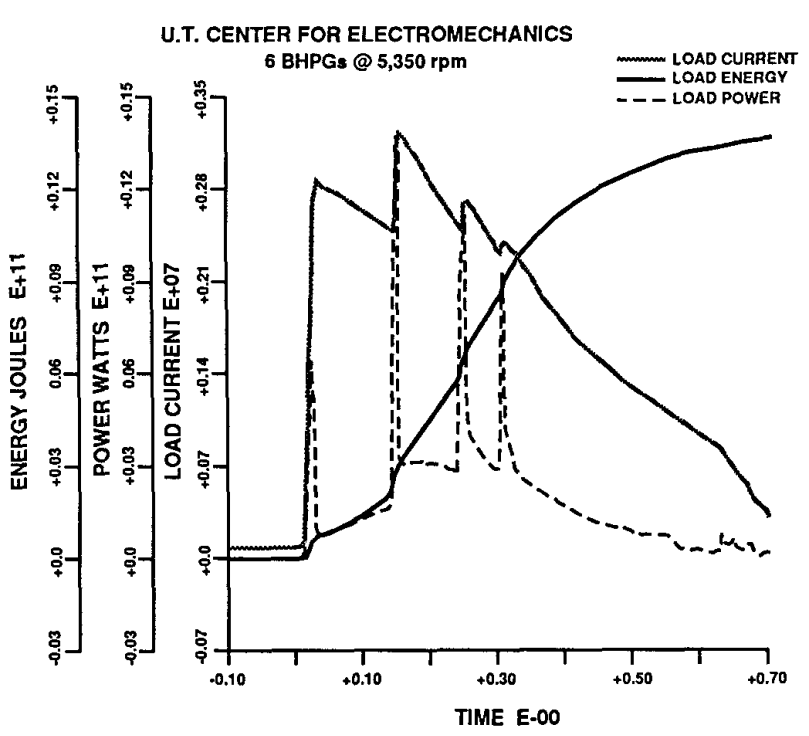

2201.0012

Figure 8. Instantaneous power and total energy delivered to load in figures 6 and 7

\section{References}

[1] W. L. Noble, J. M. Weldon, and J. H. Gully, "Final Manufacture and Assembly of a Modular 60-MJ Pulsed Homopolar Power Supply," IEEE Transactions on Magnetics, vol. Mag-22, no. 6, November 1986.

[2] J. M. Weldon and J. C. Wright, "Start-up Tests and Commissioning of a 60 MJ Pulsed Power Supply," 6th IEEE Pulsed Power Conference, pp. 96-99, 1987.

[3] D. J. Hildenbrand and R. C. Zowarka, Jr., "Characterization of the 60 MJ Balcones HPG Power Supply Circuit Parameters," 6th IEEE Pulsed Power Conference, pp. 107-110, 1987.

[4] J. H. Gully, D. J. Hildenbrand, and W. F. Weldon, "Balcones Homopolar Power Supply," IEEE Transactions on Magnetics, vol. Mag-25, no. 1, pp. 210-217, January 1989.

[5] D. J. Hildenbrand, M. A. Pichot, and J. H. Price,"Final Design of the Control and Auxiliary Systems for the Balcones Homopolar Pulse Power Supply," IEEE Transactions on Magnetics, vol. Mag-22, no. 6, pp 1516-1521, November 1986.

[6] R.L. Laughlin, et al, "System Design of the Ultrahigh Velocity GEDI Experiment," IEEE Transactions on Magnetics, vol. Mag-22, no. 6, pp. 1578-1583, November 1986.

[7] R. L. Laughlin, et al, "Fabrication and Testing of a $6.5 \mu \mathrm{H}, 1.5 \mathrm{MA}$, $100 \mathrm{kV}$ Inductor," 6th IEEE Pulsed Power Conference, pp. 457-460, 1987.

[8] R. L. Sledge, D. E. Perkins, and B. M. Rech, "High Power Switches at the Center For Electromechanics at The University of Texas at Austín," IEEE Transactions on Magnetics, vol. Mag-25, no. 1, pp. 519 524, January 1989.

[9] J. R. Kitzmiller, "Commissioning the Rotor-Bearing Systems in the Balcones $60 \mathrm{MJ}$ Modular Homopolar Power Supply at the Center for Electromechanics, Master's Thesis, The University of Texas at Austin, August, 1988. 